The headspace Brief Interventions Clinic: Increasing timely access to effective treatments for young people with early signs of mental health problems

\title{
Authors (in order)
}

Carsten Schley

Clinical Services Manager

Orygen, The National Centre of Excellence in Youth Mental Health, headspace Sunshine Visy Cares Hub, 80B Harvester Road

Sunshine, 3020, AUS

0399276222

Carsten.Schley@,orygen.org.au

Nicholas Pace

Integrated Dual Diagnosis Worker

Jesuit Social Services

Nicholas.Pace@,jss.org.au

Rhianna Mann

Contracted Allied Health Practitioner

Orygen, The National Centre of Excellence in Youth Mental Health, headspace Glenroy

Rhianna.Mann@orygen.org.au

Catherine McKenzie

Contracted Allied Health Practitioner

Orygen, The National Centre of Excellence in Youth Mental Health, headspace Werribee Cat.McKenzie@orygen.org.au

Alison McRoberts

Clinical Services Manager

Orygen, The National Centre of Excellence in Youth Mental Health, headspace Glenroy

Alison.McRoberts@orygen.org.au

Dr. Alexandra Parker

Professor

Victoria University, Institute of Sport, Exercise and Active Living

Alexandra.Parker@vu.edu.au

\section{Correspondence to:}

This is the author manuscript accepted for publication and has undergone full peer review but has not been through the copyediting, typesetting, pagination and proofreading process, which may lead to differences between this version and the Version of Record. Please cite this article as doi: 10.1111/eip.12729

This article is protected by copyright. All rights reserved. 
Carsten Schley

Clinical Services Manager

Orygen, The National Centre of Excellence in Youth Mental Health, headspace Sunshine Visy Cares Hub, 80B Harvester Road

Sunshine, 3020, AUS

0399276222

Carsten.Schley@orygen.org.au

\title{
Manuscript Title:
}

The headspace Brief Interventions Clinic: Increasing timely access to effective treatments for young people with early signs of mental disorders.

\section{Target Journal:}

Early Intervention in Psychiatry: Early Intervention in the Real World

\begin{abstract}
Aim

Timely access to treatment in the early stages of mental illness is pivotal to recovery and prevention of longer-term disablement. Yet, this can be challenging at times of growing service demands. The headspace Brief Interventions Clinic (BIC) is an innovative treatment model aiming to promote quick access to evidence-based interventions for young people presenting with early signs of mental disorders.
\end{abstract}

This article is protected by copyright. All rights reserved. 


\section{Methods}

The BIC treatment package comprises eight skill-building and behavioural intervention modules that young people can choose from. Treatment occurs over a maximum of six sessions with graduate students under supervision. Treatment outcomes are compared at baseline and final sessions, with client satisfaction measured at the final session.

\section{Results}

Allocation to the BIC occurred within 2-3 weeks of initial referral. Most young people $(73 \%)$ completed their treatment, attending on average 4 sessions. Significant reductions in overall psychological distress, depressive symptomatology, and anxiety severity ratings were observed at completion of treatment, as well as significant improvements in social and occupational functioning. Ninety-one percent of young people stated that their outcome expectations had been entirely met and 95\% were entirely satisfied with their treatment experience. A strong therapeutic relationship, specific strategies for managing emotions, coping and problem-solving, and a choice of engaging in flexible and modularised content were identified as the most valued experiences by young people.

\section{Conclusion}

The BIC might be ideally suited for health care settings aiming to promote timely access to treatments for young people with early signs of mental disorders.

\section{Keywords}

Brief interventions; young people; early intervention; timely access; anxiety disorders; depressive disorders

\section{Introduction}


It is well documented that the prevalence of mental illness in young people is the highest of any age group, making it the leading cause of premature death and loss of healthy life (Australian Institute of Health and Welfare, 2011; Kessler et al., 2007; Australian Bureau of Statistics, 2010; Gore et al., 2011). It has also been shown that early signs of mental disorders are not only a significant 'risk factor' for the development of more serious and severe mental illnesses in the future (Hickie et al., 2013 ${ }^{\text {; }}$; Yung et al., 2006; Fergusson et al., 2005; Axelson et al., 2011; Hetrick et al., 2008), but that subthreshold or attenuated illnesses in young people are already associated with high levels of psychological distress, life impairment and service use. (Hamilton et al., 2011; Hickie et al., 2007; McGorry et al., 2007). As such, timely identification and treatment targeting early stages of mental disorders are pivotal to reducing the risk of persistence and recurrence and therefore of potentially longer-term disablement (McGorry et al., 2007; Parker et al., 2016; Rickwood, et al., 2007). The 'clinical staging model' has become increasingly popular over the last decade (Patel et al., 2007) for the identification and classification of young people's mental health needs, and, to a lesser extent, for the planning and delivery of tailored interventions that 'best fit' young people's illness stage. (Hickie et al., 2013 ${ }^{\text {b }}$; Hermens et al., 2013; Cross et al., 2016). Although effective treatments are generally available for many mental disorders, engaging and developmentally appropriate interventions which target more widespread mental health problems or early signs of mental disorders in young people are presently not widely available. Cognitive Behavioural Therapy (CBT) has a substantial evidence base for psychological treatment of mental disorders in young people (Callahan et al., 2012; Hofman et al., 2012; James et al., 2013; de Silva et al., 2017). However, CBT requires the availability of specially trained clinicians to ensure high quality care and best possible outcome for young people. It has also been proposed that cognitive therapy might be 'too dense' for some young people (Brent, 2006), and that young people might actually prefer treatments that offer them a chance to be 'listened to' and to 'learn new skills' rather than to develop a deeper understanding into their problems (Fagan, 2006). There is also some indication that the behavioural components of CBT (e.g. behavioural activation and problem-solving) can be equally effective in the treatment of depression in young people compared to an 'all 
components' CBT approach (Hetrick et al., 2015). This is also reflected in the current depression treatment guidelines for clinicians (NICE, 2015). As such, the question remains which elements of psychological treatment are the most feasible and effective interventions for young people who are experiencing milder forms of mental health disorders, or indeed are not yet fulfilling criteria for a diagnosable mental illness.

Lastly, young people are known to be the least likely of all age groups to access and receive professional help for their mental health problems (Rickwood et al., 2007; Australian Institute of Health and Welfare, 2011). As such, engaging, youth-specific treatment models are pivotal.

\section{The Service Context}

headspace is a world-first youth mental health initiative that supports young people who are "going through a tough time" (Rickwood et al., 2015). The youth-friendly services at headspace are aimed at teenagers and young adults in recognition that 75 percent of mental disorders emerge before the age of 25 years (Kessler et al., 2007). Orygen, the National Centre of Excellence in Youth Mental Health operates four headspace centres and associated services in in the northern and western regions of Melbourne (Glenroy, Sunshine, Werribee and Craigieburn).

Where there is a need...there is a way

Referrals of young people to headspace centres have notably increased since their inception, both in relation to total numbers of young people and those with greater complexity of needs (Hilferty et al., 2015). This development has made it challenging to guarantee timely access for young people with 'lesser needs', as those with more significant problems demanded prioritisation. As timely access to care is a priority area for headspace, the need for an alternative treatment model was identified, resulting in the creation of the 'Brief Interventions Clinic' (BIC). 


\section{Methods}

What is BIC?

The BIC 'pack' builds on the methods and findings of the Simple Interventions Trial (Parker et al., 2016) (SIT) conducted at our Sunshine and Glenroy centres between 2009 and 2012. This study compared the effects of a psychological intervention (problem solving therapy versus supportive counselling) and a physical activity intervention (behaviour change versus psychoeducation). Whilst both treatments led to significant improvements in depression and anxiety symptoms over the course of the 6-week intervention period, young people in the physical activity intervention group showed the greatest improvement regardless of the type of psychotherapy received.

In addition to the SIT treatment modules, the BIC pack comprised a set of well described skill-building and behavioural strategies in line with common presenting problems of young people seeking our assistance (e.g. problems with self-esteem or anger management) (Table 1). All interventions included in the BIC were consistent with the Australian guidelines for the management of anxiety and depressive disorders in young people (McDermott et al., 2010; Reavley et al., 2010).

BIC was launched at two centres (Sunshine and Glenroy) in September 2012 and over the following two years underwent a number of revisions to both content and design, most notably, young people from the Youth Advisory Groups (YAG) of our centres were involved in re-writing the modules to increase the 'voice' of young people throughout. In March 2016 the BIC model was published as the "Brief Interventions in Youth Mental Health Toolkit" (Orygen, 2016) and made freely available to every Australian-based headspace centre.

\section{Pathway to BIC}

Young people allocated to the BIC were identified in line with the standard intake process at the headspace centre. Once referred, young people were seen by a post-graduate mental health clinician who conducted the headspace bio-psycho-social assessment (Parker et al., 
2010). If the assessing clinician concluded that the young person presented with a general mental health problem or mild to moderate levels of mental disorder, low level of risk to self/others and limited complexity (i.e. 'simple' rather than multiple needs) the young person was offered to partake in the BIC (except where there was no vacancy available at the time, in which case the young person was allocated as per 'the usual pathway', typically involving being seen by a centre-based privately contracted allied health professional under Medicare (Department of Health, 2015)). Young people were given information about the BIC and that they would be seen by an allied-health trainee clinician (further referred to as 'graduate student/s'). If the young person agreed to enroll in the BIC they received a maximum of six treatment sessions, typically on a weekly basis. Young people had an active role in choosing the module/s they thought the 'best fit' for their needs. If the young person did not agree to become involved with the BIC they were able to access the 'usual pathway' as mentioned above. As with any service or treatment at headspace, young people were informed that their participation in the BIC was completely voluntary and that they could chose to withdraw at any stage. Treatment progress was monitored by completing a set of psychometric measures at the initial and final session (see Table 2). To ensure consistency and high quality in the delivery of interventions, students received training in the administration of each BIC module as well as outcome measurement. Additionally, students received individual and group supervision with a senior Clinical Psychologist to review their practice.

The data included in this paper is based on outcome measures for young people engaged in the BIC across the four Orygen headspace centres between September 2012 and July 2017. The BIC evaluation received ethics approval by the Centre for Youth Mental Health - Human Ethics Advisory Group of The University of Melbourne (ID: 1750128).

\section{Description of measures}

Demographic information was obtained from the young person's initial registration with the headspace centre and, where available, from the headspace 'Minimum Data Set' (MDS) (headspace National Youth Mental Health Foundation, 2014). 
The Kessler Psychological Distress Scale 10 (K10) (Kessler et al., 2002) was used to determine a young person's 'overall level' of psychological distress over the last four weeks. The young person's K10 ratings were obtained in the first and final sessions either from the headspace MDS or, in case they had not already completed the MDS on the day, during their session.

The Quick Inventory of Depressive Symptoms (QIDS) (Trivedi et al., 2004; Rush et al., 2003 ) is a rating scale that assesses the nine criterion symptom domains designated by the American Psychiatric Association's (2000) DSM-IV to diagnose a major depressive episode. Young people were asked to rate the QIDS at the first and final session based on their experience over the preceding week.

The Overall Anxiety Severity and Impairment Scale (OASIS) (Norman et al., 2006) is a fiveitem measure that assesses frequency of anxiety, intensity of anxiety symptoms, anxietyrelated behavioural avoidance, and functional impairment associated with anxiety. Young people were asked to complete the OASIS at the first and final session based on their experience over the past week.

The Social and Occupational Functioning Assessment Scale (SOFAS) (Goldman et al., 1992) is a clinician-rated measure of an individual's level of social and occupational functioning based on a scale from 1 to 100, with higher ratings indicating a higher level of functioning. The SOFAS was completed by the treating graduate student at the time of the first and final session, reflecting the level of functioning at the time of the rating.

In consultation with young people from the centre's YAG, a set of seven questions (Table 4) were identified aiming to assess the subjective (qualitative) experience of young people who graduated from the BIC. Young people were asked to score questions on a six-point Likert scale (ranging from 'not at all' to 'definitely') at the time of their final session. Additionally, 
young people were prompted to freely express what they personally liked 'most' and 'least' about their experience in the BIC. To reduce a possible 'desirability effect', young person provided their feedback without the presence of the graduate student.

\section{Data Analysis}

Demographic data was analysed using standard descriptive statistics. Mean changes on psychometric measures between first and final treatment sessions were calculated using onesample t-tests for those young people with data at both time points. Effect sizes were established using Cohen's $d$ and interpreted as small (0.2), medium (0.5) and large (0.8). (Cohen, 1988). Possible correlations between variables was determined by employing the Chi-Square Test. Qualitative feedback from Likert scale ratings was analysed in relation to the percentage of young people who 'definitely agreed' with a question (i.e. who selected the maximum of ' 6 ' on the rating scale). Free-text feedback from young people was analysed using thematic cluster analysis.

\section{Results}

One hundred and twenty-two young people were engaged with the BIC across the four headspace centres (Table 2). Young people who identified as male gender were overrepresented in the sample (Male $=62 \%$; Female $=38 \%$; Other $=0 \%$ ) and the 'younger' cohort of 12 to 17 -year-olds made up roughly $70 \%$ of the BIC graduates. Seventy-three percent of young people presented with either no specific symptoms of mental disorder (Hickie et al., 2013 ; Stage $0(16.7 \%)$ ) or mild to moderate general symptoms of mental health problems (Ibid; Stage 1a (56.3\%)) at the time of commencement in the BIC . However, almost one third of young people (29\%) who were engaged with the BIC met

\footnotetext{
${ }^{1}$ Data on 'clinical staging' was only available for young people seen since January 2015 in line with headspace Minimum Data Set developments and access restrictions. As such, the sample size for our reporting was reduced to n=48 (i.e. $59 \%$ of the original cohort).
} 
criteria for 'stage 1b' (12.5\%) or higher clinical stage (14.6\%), i.e. they either had subthreshold mental disorders or met criteria for one or more diagnosable mental illnesses. On average, young people were able to commence treatment in the BIC within 18 days of their initial contact with the centre $(M=17.6 ; S D=11.9 ; M i n=0 ; M a x=49)$. Seventy-three percent of young people completed their treatment in a planned manner (i.e. had a mutually agreed ending with their graduate student). Forty-eight percent of young people attended the maximum number of six treatment sessions $(\mathrm{M}=4.3 ; \mathrm{SD}=1.9)$. There was no significant difference between gender and treatment completion rates $\left(\lambda^{2}=.089 ; \mathrm{df}=1 ; \mathrm{p}=.765\right)$, however males tended to drop-out less (male completers $=58$; female completers $=34$ ). Although young people 21 years and older tended to be more likely to drop out of the BIC, age was statistically independent from retention rates overall $\left(\lambda^{2}=3.28 ; \mathrm{df}=4 ; \mathrm{p}=.511\right)$. Young women and men did equally well on all outcome measures regardless of age or centre they were seen at (see Table 3). The most preferred treatment modules were 'Understanding My Moods and Anxiety' (77\%) and 'Problem Solving Skills' (55\%). Least chosen were 'Physical Activity for Wellbeing' (14.8\%) and 'Understanding and Accepting Myself' (7.3\%) (Table 1). On average, young people selected three modules during their involvement in the BIC. Following BIC, $30 \%$ of young people did continue to access psychological support at the headspace centre. There were no significant statistical associations between young people receiving additional care following $\mathrm{BIC}$ and their gender, age, or any of the psychometric outcomes (Gender: $\lambda^{2}=1.43 ; \mathrm{df}=1 ; \mathrm{p}=.230$; Age groups: $\lambda^{2}=5.53 ; \mathrm{df}=4 ; \mathrm{p}=.236$; QIDS: $\lambda^{2}=4.85 ; \mathrm{df}=4 ; \mathrm{p}=.303$; OASIS: $\lambda^{2}=1.36 ; \mathrm{df}=1 ; \mathrm{p}=.243$; SOFAS: $\lambda^{2}=4.12 ; \mathrm{df}=4 ; \mathrm{p}=.389$ ). However, young people who scored in the 'well' category of the K10 at their last BIC session tended to be less likely to seek follow-on support $\left(\lambda^{2}=7.39 ; \mathrm{df}=3 ; \mathrm{p}=.060\right)$.

Pre-post comparison of psychometric measures for young people with data at either time point showed significant reductions on K10, QIDS and OASIS as well as significant improvements on the SOFAS following treatment (Table 2). The effect sizes post BIC were in the range of $d=0.59$ to 0.75 , indicating a medium effect size across the symptoms and functioning variables (Table 2). Based on the assessment of the treating graduate students, occupational and social functioning of young people improved equally across age groups, genders and irrespectively of the number of completed sessions. Following involvement in 
the BIC, significantly more young people scored in the 'non-clinical' range on a given psychometric measure compared to the time of the initial session (Figure 1). Likewise, more young people were identified as being in a 'lower' clinical stage of illness by the end of their treatment in the BIC (Table 2). However, this 'shift' was not statistically significant $\left(\lambda^{2}=15.19 ; \mathrm{df}=12 ; \mathrm{p}=.231\right)$.

There were some insignificant correlations between demographic variables and psychometric treatment outcomes (Table 3). Notably, young people who 'dropped out' (left in an unplanned manner) showed equal improvements in their functioning compared to those who competed treatment in a planned manner. Although some differences in ratings were observed between headspace centres these were not significantly related to treatment outcomes overall (Table 3), with exception of changes in ratings on the K10, which were found significantly 'less favourable' in the Craigieburn centre. This is however likely a reflection of the very low numbers of young people with available data at that centre $(n=5)$, rather than a true representation for 'worse outcome'.

Results from qualitative post-treatment rating scales yielded a consistent finding of 'definite agreement' with the evaluative questions, with 95\% indicating that they were entirely satisfied with their experience in the BIC (Table 4). Responses to the open-ended questions about what was liked 'most' and 'least' about the BIC were examined using thematic analysis and exemplar quotes from each theme are provided. Categories within four prominent themes were identified (Table 5). Adhering to the qualitative reporting framework of Hill et al. (1997), only the identified themes that were mentioned by at least some of the participants (that is, 21-50\%) will be discussed. Most participants identified the benefits of the therapeutic relationship, with some directly commenting on the importance of being heard, supported and understood throughout the intervention period.

"That my therapist listened to everything I said, understood where my point of views were coming from and is very caring."

Some participants identified the importance of learning strategies that assisted in coping with distress or specific problem-solving skills. 
"Learning different ways of coping with certain things and getting to sleep."

Some young people identified changes in their symptoms or functioning as something they liked from participating in BIC.

"I can now control my anger a bit better and I'm not fighting with my father as much."

The final identified theme regarding the benefits of the intervention described the content and processes of BIC, including the modular and flexible approach and interactive session content.

"The many modules. I liked that I could work on many areas separately - this made everything clearer to understand. Also liked that I could select modules that were most relevant to me."

When asked for recommendations for improvements, most participants reported satisfaction with BIC and identified that their needs were met.

"Everything was great, no improvements needed."

\section{Discussion}

Effective early intervention models for young people with more general mental health problems and early signs of mental health disorders have been called for; yet there is a lack of such models presently.

The Brief Interventions Clinic (BIC) described in this report may well be the first intervention package that combines a youth-specific approach informed directly 'by the voice of young people', with the available 'evidence base' for psychological interventions for young people at an early stage of developing problems with their mental health.

This article is protected by copyright. All rights reserved. 
With previous average allocation periods of about 5 weeks, and up to 14 weeks at times of peak demand ( ${ }^{2} \mathrm{M}=5.31 ; \mathrm{SD}=3.23$; $\mathrm{Min}=0.14$; $\left.\mathrm{Max}=14\right)$, the implementation of the BIC across our headspace centres has significantly increased the likelihood of young people with mental health problems receiving access to care before their problems potentially become more debilitating. Busy youth (primary) mental health services hoping to promote timely care for young people may therefore be interested in considering the BIC as part of their service model.

The high proportion of young people who completed the BIC (with exception of 12 young people at one of our centres), combined with the feedback of those who choose to provide it ( $78 \%$ of 122 young people), suggests that the BIC intervention model may foster engagement and treatment retention in young people; hence may improve chances for favourable mental health outcomes. Given that young people are often prone to dropping out of mental health treatment prematurely (Rickwood et al., 2015) the BIC could offer an important addition to the current platform of care available to young people. As this study found equal retention rates and outcomes between the genders, the BIC may be particularly suited to the mental health care of young males who, statistically, are less likely to seek and engage in assistance for their mental health problems (Rice et al., 2017; Australian Institute of Health and Welfare, 2011). Also promising is the finding of comparable retention rates and outcomes across the entire age range of 12 to 25 year-olds. However, since the older cohort tended to 'drop out' somewhat more, the suitability of the BIC for this age group might benefit from further evaluation. A focus group review with people 21 years and older would be ideally suited for this purpose.

Positive changes with medium effect sizes in clinical symptoms/psychological distress and social and occupational functioning following participation in the $\mathrm{BIC}$ are promising, especially since outcomes are (statistically) equally positive across gender and age groups. However, more importantly perhaps, subjective feedback from young people who did share their views indicates that they intrinsically perceived BIC interventions as helpful to them. In line with previous findings, we suggest that if young people believe that their needs are

\footnotetext{
${ }^{2}$ Based on internal referral data of the four Orygen headspace centres collected between January and July 2017 . Waiting time is defined as the difference (number of weeks) between initial referral and first appointment with a centre-based allied-health clinician.
} 
responded to in a way they expect and prefer, they are more likely to be motivated to engage with and stay in treatment (Robinson et al., 2008; Swift et al., 2009; Schley et al., 2012).

The finding that around $30 \%$ of young people continued at access mental health support following BIC despite their high levels of satisfaction with outcomes during BIC poses an interesting question about the relationship between 'outcome expectations' and seeking of assistance. Unfortunately, a satisfactory answer to this question is beyond the scope of the current study.

Four themes were identified from open-ended feedback responses, highlighting that young people found that a strong therapeutic relationship, specific strategies for managing emotions, coping and problem-solving skills and choice of engaging in flexible and modularised content to be the main strengths of the intervention.

Although this was not formally evaluated, based on feedback from our graduate students over the last five years, BIC interventions can be feasibly delivered by trainee clinicians under supervision. Given that (mental) health services for young people are often struggling to meet increasing demand (Patel et al., 2007), the BIC may well have both positive resource and workforce implications.

\section{Limitations and Future Outlook}

Given the naturalistic real-world design of this study the results need to be interpreted with caution. It is possible that the drop-out of young people and consequent loss of post-treatment data may have inflated the positive findings of this study both in terms of psychometrics and qualitative feedback. However, an overestimation of results might to an extent be mitigated by our finding of improved functioning regardless of whether young people 'dropped out' or finished their treatment in a planned manner. Even though the assessment of graduate students may have been influenced by a possible desire to rate the functioning of their clients as improved at the end of treatment, the fact that they did not have access to their previous ratings (completed at the first session), would have reduced this potential bias. Given that 
young people emphasised the importance of the therapeutic alliance, the qualitative measures at their final session may have been susceptible to a positive response bias even though they were completed without the graduate student being present.

As this study is non-randomised and not controlled, and had great flexibility in relation to what young people engaged/not engaged with, no firm conclusions can be drawn at this stage about the 'effectiveness' of the BIC. Given that the 'Physical Activity for Wellbeing' module was the least utilised in this cohort despite being previously shown as the most effective element in the Simple Interventions Trial (Parker et al., 2016) warrants further exploration. A future randomised controlled trial ('dismantling' study) would be an ideal design to investigate whether the use of certain modules might lead to better outcomes, or whether young people's outcomes are dependent on how many sessions they spend on modules. Despite the absence of randomisation and controlled conditions, our results are nonetheless encouraging given the positive appraisal by young people and replication of earlier findings (Parker et al., 2016; Eskin et al., 2008; Bru et al., 2013).

The current design and measures used to collect data do not allow a differentiated view of change or maintenance of gains over time. It would therefore be of interest to undertake a longitudinal follow-up study to investigate whether an early intervention model like the BIC has lasting effects on reducing the risk for re-emergence of mental health problems/disorders and longer-term disablement. A bigger sample size would also be useful to make findings more generalisable.

\section{Conclusions}

The BIC might be ideally suited as a treatment model in (primary) health care services aiming to ensure timely access to effective care for young people experiencing early problems with their mental health. This 'real-world' preliminary evaluation indicates it is an acceptable intervention that is feasible to deliver. Further research is required to consolidate the effectiveness of the BIC model. 


\section{Acknowledgements}

The authors would like to thank all members of the Youth Advisory Groups who have been involved in the revision of the BIC pack. Additionally, we'd like to thank all our students who have been delivering the interventions and who have assisted us in developing the model.

This article is protected by copyright. All rights reserved. 


\section{References}

American Psychiatric Association. (2000). Diagnostic and statistical manual of mental disorders, (4th ed.). Washington, DC: American Psychiatric Association.

Australian Bureau of Statistics (2010). Mental health of young people in Australia, 2007. Canberra: Australian Bureau of Statistics.

Australian Institute of Health and Welfare (2011). Young Australians: their health and wellbeing 2011 Cat. no. PHE 140. Canberra: AIHW.

Axelson, D.A., Birmaher, B., Michael, A., Dr. Michael A. Strober, M.S., Goldstein, B.I., Ha, W., Gill, M.K., Goldstein, G.R., Yen, S., Hower, H., Hunt, J.I., Fangzi, L., Iyengar, S., Dickstein, D., Kim, E., Ryan, N.R., Frankel, E., \& Keller, M.B. (2011). Course of subthreshold bipolar disorder in youth: diagnostic progression from bipolar disorder not otherwise specified. Journal of the American Academy of Child and Adolescent Psychiatry, 50, 1001-16.

beyondblue (2010). Clinical practice guidelines: Depression in adolescents and young adults. Melbourne: beyondblue.

Brent, D.A. (2006). Glad for what TADS adds, but many TADS grads still sad. Journal of the Academy of Child and Adolescent Psychiatry, 45, 1461-1464.

Brent, D.A., \& Birmaher, B. (2002). Adolescent depression. New England Journal of Medicine, 347, 667-671.

Bru, L., Solholm, R., \& Idsoe, T. (2013). Participants' experiences of an early cognitive behavioral intervention for adolescents with symptoms of depression. Emotional and Behavioural Difficulties, 18, 24-43.

Callahan, P., Liu, P., Parker, A.G., Purcell, R., \& Hetrick, S.E. (2012). Evidence map of prevention and treatment interventions for depression in young people. Depression Research and Treatment, doi:10.1155/2012/820735, 1-11.

Cohen, J. (1988). Statistical power analysis for the behavioural sciences (2nd Ed.). New Jersey, USA: Laurence Erlbaum Associates

Cross, S.P., Hermens, D.F., \& Hickie, I.B. (2016). Treatment patterns and short-term outcomes in an early intervention youth mental health service. Early Intervention in Psychiatry, 10, 88-97. 
Department of Health (2015). Better Access to Psychiatrists, Psychologists and General Practitioners through the MBS (Better Access) initiative.

http://www.health.gov.au/internet/main/publishing.nsf/Content/mental-ba. [Downloaded on 18/09/2017]

de Silva, S., Bailey, A.P., Parker, A.G., Montague, A., \& Hetrick, S.E. (2017). An OpenAccess Evidence Database of Controlled Trials and Systematic Reviews in Youth Mental Health. Early Intervention in Psychiatry, ePub ahead of print. doi:10.1111/eip.12423

Eskin, M., Ertekin, K., \& Demir, H. (2008). Efficacy of a problem-solving therapy for depression and suicide potential in adolescents and young adults. Cognitive Therapy and Research, 32, 227-245.

Fagan, R. (2006). Counseling and treating adolescents with alcohol and other substance use problems and their families. The Family Journal: Counseling and Therapy for Couples and Families, 14, 326-333.

Fergusson, D., Horwood, L., Ridder, E., \& Beautrais, A. (2005). Subthreshold depression in adolescence and mental health outcomes in adulthood. Archives of General Psychiatry, 62, 66-72.

Goldman, H.H., Skodol, A.E., \& Lave, T.R. (1992). Revising Axis V for DSM-IV: A Review of Measures of Social Functioning. American Journal of Psychiatry, 149, 11481156.

Gore, F.M., Bloem, P.J.N., Patton, G.C., Ferguson, J., Joseph, V., Coffey, C., \& Mathers, C.D. (2011). Global burden of disease in young people aged 10-24 years: A systematic analysis. The Lancet, 377, 2093-2102.

Hamilton, B.A., Naismith, S.L., Scott, E.M., Purcell, S., \& Hickie, I.B. (2011). Disability is already pronounced in young people with early stages of affective disorders: Data from an early intervention service. Journal of Affective Disorders, doi:10.1016/j.jad.2010.10.052.

headspace National Youth Mental Health Foundation (2014). Clinical Governance Framework. Governance System 4: Quality Improvement and Risk System. Canberra: Australian Government Department of Health and Ageing. 
Hermens, D.F., Naismith. S., Lagopoulos, J., Lee, R.S., Guastella, A.J., Scott, E.M., \&, Hickie, I.B. (2013). Neuropsychological profile according to the clinical stage of young person's presenting for mental health care. BMC Psychology, 1, 8.

Hetrick, S.E., Cox, G.R., Fisher, C., Bhar, S., Rice, S., Davey, C., \& Parker, A.G. (2015). Back to basics: could behavioural therapy be a good treatment option for youth depression? A critical review. Early Intervention in Psychiatry, 9, 93-99. doi:10.1111/eip.12142.

Hetrick, S.E., Parker, A.G., Hickie, I.B., Purcell, R., Yung, A.R., \& McGorry, P.D. (2008). Early identification and intervention in depressive disorders: towards a clinical staging model. Psychotherapy and Psychosomatics, 77, 263-70.

Hickie, I.B., Davenport, T.A., Luscombe, G.M., Rong, Y., Hickie, M.L., Bell, M.I. (2007). The assessment of depression awareness and help-seeking behaviour: experiences with the International Depression Literacy Survey. BMC Psychiatry, 7, 48. doi.org/10.1186/1471-244X-7-48.

Hickie, I.B., Scott, E.M., Hermens, D.F., Naismith S.L., Guastella, A.J., Kaur, M., Sidis, A., Whitwell, B., Glozier, N., Davenport, T., Pantelis, C., Wood, S.J., \& McGorry, P.D. $\left(2013^{\mathrm{a}}\right)$. Applying clinical staging to young people who present for mental health care. Early Intervention in Psychiatry, 7, 31-43.

Hickie, I.B., Hermens, D.F., Naismith, S., Guastella, A.J., Glozier, N., Scott, J., \& Scott, E.M. $\left(2013^{\mathrm{b}}\right)$. Evaluating differential developmental trajectories to adolescentonset mood and psychotic disorders. BMC Psychiatry, 2013, 303-3. doi: 10.1186/1471-244x-13-303 29.

Hill, C.E., Thompson, B.J., \& Williams, E.N. (1997). A guide to conducting consensual qualitative research. The Counselling Psychologist, 25, 517-572.

Hilferty, F., Cassells, R., Muir, K., Duncan, A., Christensen, D., Mitrou, F., Gao, G., Mavisakalyan, A., Hafekost, K., Tarverdi, Y., Nguyen, H., Wingrove, C., \& Katz, I. (2015). Is headspace making a difference to young people's lives? Final Report of the independent evaluation of the headspace program. (SPRC Report 08/2015). Sydney: Social Policy Research Centre, UNSW Australia. 
Hofmann, S. G., Asnaani, A., Vonk, I. J. J., Sawyer, A. T., \& Fang, A. (2012). The Efficacy of Cognitive Behavioral Therapy: A Review of Meta-analyses. Cognitive Therapy and Research, 36, 5, 427-440. http://doi.org/10.1007/s10608-012-94761.

James, A.C., James, G., Cowdrey, F.A., Soler, A., \& Choke, A. (2013). Cognitive behavioural therapy for anxiety disorders in children and adolescents. Cochrane Database of Systematic Reviews, 3, CD004690. doi:10.1002/14651858.CD004690.pub3.

Yung, A.R., Stanford, C., Cosgrave, E., Killackey, E., Phillips, L., Nelson, B., \& McGorry, P.D. (2006). Testing the Ultra High Risk (prodromal) criteria for the prediction of psychosis in a clinical sample of young people. Schizophrenia Research, 84, 5766.

Kessler, R.C., Amminger, G.P., Aguilar-Gaxiolac, S., Alonsod, J., Lee, S., \& Bedirhan Ustun, T. (2007). Age of onset of mental disorders: a review of recent literature. Current Opinion in Psychiatry, 20, 359-364.

Kessler, R.C., Andrews, G., Colpe, L.J., Hiripi, E., Mroczek, D.K., Normand, S.L., Walters, E.E., \& Zaslavsky, A.M. (2002). Short screening scales to monitor population prevalences and trends in non-specific psychological distress. Psychological Medicine, 32, 959-956.

McDermott, B., Baigent, M., Chanen, A., Fraser, L., Graetz, B., Hayman, N., Newman, L., Parikh, N., Peirce, B., Proimos, J., Smalley, T., \& Spence, S.; beyondblue Expert Working Committee (2010). Clinical practice guidelines: Depression in adolescents and young adults. Melbourne: beyondblue.

McGorry, P.D., Purcell, R., Hickie, I.B., \& Jorm, A.F. (2007). Investing in youth mental health is a best buy. Medical Journal of Australia, 187, 5-7.

NICE (2015). Depression in children and young people: Identification and management in primary, community and secondary care (Clinical Guideline 28). United Kingdom: National Institute for Health and Care Excellence. 
Norman, S.B., Hami-Cissell, S., Means-Christensen, A.J., Stein, M.B. (2006). Development and Validation of an Overall Anxiety Severity and Impairment Scale (OASIS). Depression and Anxiety, 23, 245-249.

Orygen, The National Centre of Excellence in Youth Mental Health (2016). The brief interventions in youth mental health toolkit: A clinical resource for headspace centres. Orygen, The National Centre of Excellence in Youth Mental Health. Melbourne: Australia.

Patel, V., Flisher, A.J., Hetrick, S., \& McGorry, P.D. (2007). The Lancet, 369, 1302-13. DOI: 10.1016/S0140-6736(07)60368-7.

Parker, A.G., Hetrick, S.E., \& Purcell, R. (2010). Assessment of mental health and substance use disorders in young people: Refining and evaluating a youth-friendly assessment interview. Australian Family Physician, 39, 585-588.

Parker, A.G., Hetrick, S.E., Jorm, A.F., MacKinnon, A.J., Yung, A.R., McGorry, P.D., Purcell, R. (2016). The effectiveness of simple psychological and physical activity interventions for high prevalence mental health problems in young people: A factorial randomised controlled trial. Journal of Affective Disorders, 196, 200-209.

Reavley, N., Allen, N.B., Jorm, A.F., Morgan, A.J., \& Purcell, R. (2010). A Guide to What Works for Anxiety Disorders. Melbourne: beyondblue.

Rice, S.M., Telford, N., Rickwood, D., \& Parker, A.G. (2017). Young men's access to community-based mental health care: Qualitative analysis of barriers and facilitators. Journal of mental health, Online, 1-7. doi:0.1080/09638237.2016.1276528

Rickwood, D.J., Deane, F.P., Wilson, C.J. (2007). When and how do young people seek professional help for mental health problems? Medical Journal of Australia, 187, 35-39.

Rickwood, D. J., Telford, N., Mazzer, K., Tanti, C., Parker, A. G., \& McGorry, P. D. (2015). Services provided to young people through the headspace centres across Australia. Medical Journal of Australia, 202, 533-536. doi:10.5694/mja14.01695 
Robinson, J.H., Callister, L.C., Berry, J.A., \& Dearing, K.A. (2008). Patient-centered care and adherence: definitions and applications to improve outcomes. Journal of the American Academy of Nurse Practitioners, 20, 600-07.

Rush, A.J., Trivedi, M.H., Ibrahim, H.M., Carmody, T.J., Arnow, B.K., Markowitz, D.N., Ninan, J.C., Kornstein, P.T., Manber, S., Thase, R., Kocsis, M.E., Keller, J.H., \& Martin, B. (2003). The 16-Item Quick Inventory of Depressive Symptomatology (QIDS), clinician rating (QIDS-C), and self-report (QID-SR): a psychometric evaluation in patients with chronic major depression. Biological Psychiatry, 54, 573-83.

Schley, C., Yuen, K., Fletcher, K. \& Radovini, A. (2012). Does engagement with an intensive outreach service predict better treatment outcomes in 'high-risk' youth? Early Intervention in Psychiatry, 6, 176-184.

Swift, J.K., \& Callahan, J.L. (2009). The Impact of Client Treatment Preferences on Outcome: A Meta-Analysis. Journal of Clinical Psychology, 65, 368-81.

Trivedi, M.H., Rush, A.J., Ibrahim, H.M., Carmody, T.J., Biggs, M.M., Suppes, T., Crismon, M.L., Shores-Wilson, K., Toprac, M.G., Dennehy, E.B., Witte, B., \& Kashner, T.M. (2004). The Inventory of Depressive Symptomatology, Clinician Rating (IDS-C) and Self-report (IDS-SR), and the Quick Inventory of Depressive Symptomatology, Clinician Rating (QIDS-C) and Self-report (QIDS-SR) in public sector patients with mood disorders: A psychometric evaluation. Psychological Medicine, 34, 73-82.

This article is protected by copyright. All rights reserved. 
Tables

Table 1: Description and aims of the eight BIC treatment modules.

\section{Communicating with Confidence}

This module has been developed to assist young people in developing assertive communication skills, drawing upon a Cognitive Behavioural Therapy framework. The focus of the module is to help young people develop an understanding of how they communicate, to consider alternative perspectives in social situations, and the advantages of assertiveness in addressing needs.

\section{Exercise for Wellbeing}

Exercise for Wellbeing aims to deliver relevant and recent psychoeducation and intervention for young people designed to give them a 'kick-start' to getting active again to alleviate low mood and increase motivation, potentially impacting on a young person's overall health.

\section{Problem Solving Skills}

This module has been developed to assist young people to effectively solve their own problems. The focus of the module is to introduce young people to the systematic problem solving approach in an accessible way so that they can practice in session and easily replicate the approach on their own.

\section{Understanding and Accepting Myself}

\section{Understanding My Anger}

This module has been developed to assist young people presenting with mild to moderate anger and aggression management concerns. The focus of the module is to increase awareness and insight into emotional response with the view to understanding consequences of behaviours to improve relationships with others and the self.

\section{Understanding My Moods and Anxiety}

This module has been developed to assist young people presenting with mild to moderate depression and anxiety. Drawing on Cognitive Behavioural Therapy and Acceptance and Commitment Therapy, the focus of this module is to develop resiliency in young people by being able to notice and challenge unhelpful thoughts and accept rather than attempt to control and/or avoid unpleasant feelings.

\section{Mindfulness \& Relaxation}

This module is designed to give young people a basic understanding of mindfulness and an introduction to mindfulness and relaxation techniques. Specifically, the focus is placed on sampling different strategies until the young person finds a technique that works for them.

\section{Sleeping Well}


This module has been developed to assist young people presenting with mild to moderate body image concerns and has been written from an Acceptance and Commitment Therapy framework. The focus of the module is moving away from control (controlling internal experiences or external appearances) and avoidance (avoiding internal or external experiences) towards self-acceptance.
This module is designed to assist young people to recognise their current sleep habits in the context of other concerns or stressor in their life. More specifically, the focus is placed on the impacts of sleep rather than negatively viewing sleep as problematic.

Table 2: Main outcomes combined and separately by headspace centre.

\begin{tabular}{|c|c|c|c|c|c|c|}
\hline & \multicolumn{2}{|c|}{ All } & Sunshine & Glenroy & Craigieburn & Werribee \\
\hline & $\mathrm{N}$ & 122 & 64 & 41 & 12 & 5 \\
\hline \multirow{2}{*}{ Gender } & Male \% & 62 & 61 & 66 & 67 & 40 \\
\hline & Female \% & 38 & 39 & 34 & 33 & 60 \\
\hline \multirow{2}{*}{ Age $($ Range $=12-25 y r s)$} & M & 16.9 & 17.3 & 16.4 & 15.9 & 17.2 \\
\hline & SD & 3.35 & 3.26 & 3.38 & 3.06 & 3.81 \\
\hline \multirow{4}{*}{ Waiting time (days) } & Min & 0 & 0 & 0 & 0 & 5 \\
\hline & Max & 49 & 48 & 49 & 45 & 20 \\
\hline & M & 17.2 & 15.39 & 20.78 & 17.33 & 11 \\
\hline & SD & 11.64 & 10.17 & 13.01 & 13.53 & 6.36 \\
\hline \multirow{2}{*}{ No. of sessions completed } & M & 4.34 & 4.81 & 4.20 & 3.17 & 2.20 \\
\hline & SD & 1.91 & 1.76 & 1.87 & 2.08 & .837 \\
\hline Drop-out rate & $\%$ & 24.6 & 21.9 & 24.4 & 41.7 & 20.0 \\
\hline Support after BIC & $\%$ & 30.3 & 32.8 & 17.1 & 50.0 & 60.0 \\
\hline $\mathrm{K} 10^{\dagger}$ pre-treatment & Min & 10 & 10 & 10 & 12 & 19 \\
\hline
\end{tabular}




\begin{tabular}{|c|c|c|c|c|c|c|}
\hline & Max & 44 & 44 & 34 & 37 & 39 \\
\hline & M & 23.56 & 25.00 & 20.78 & 23.17 & 28.80 \\
\hline & SD & 7.92 & 8.26 & 6.56 & 8.10 & 8.07 \\
\hline \multirow{4}{*}{ K10 post-treatment } & Min & 10 & 10 & 10 & 14 & 16 \\
\hline & Max & 50 & 50 & 25 & 31 & 35 \\
\hline & $\mathrm{M}$ & 17.88 & 17.86 & 16.52 & 21.00 & 22.75 \\
\hline & SD & 7.16 & 8.38 & 3.74 & 6.96 & 8.73 \\
\hline \multirow{5}{*}{$\mathrm{K} 10$ post minus pre } & $\mathrm{n}$ & 77 & 43 & 25 & $5^{\pi}$ & 4 \\
\hline & Mean-diff & -5.68 & -7.14 & -4.26 & n.a. & n.a. \\
\hline & $t / d f$ & $21.89 / 76$ & $13.96 / 42$ & $22.06 / 24$ & n.a. & n.a. \\
\hline & p-value & $<.000$ & $<.000$ & $<.000$ & n.a. & n.a. \\
\hline & Effect size $d$ & 0.75 & & & & \\
\hline \multirow{4}{*}{ QIDS* pre-treatment } & Min & 0 & 0 & 1 & 3 & 9 \\
\hline & Max & 37 & 37 & 19 & 20 & 19 \\
\hline & M & 10.46 & 11.02 & 9.05 & 11.18 & 13.0 \\
\hline & SD & 5.57 & 5.91 & 4.91 & 5.87 & 4.18 \\
\hline \multirow{4}{*}{ QIDS post-treatment } & Min & 1 & 1 & 1 & 6 & 17 \\
\hline & Max & 23 & 23 & 17 & 19 & 17 \\
\hline & M & 7.00 & 6.69 & 6.35 & 10.60 & 17.0 \\
\hline & SD & 4.84 & 4.83 & 4.24 & 5.22 & 0.00 \\
\hline \multirow{5}{*}{ QIDS post minus pre } & $\mathrm{n}$ & 71 & 42 & 23 & $5^{\pi}$ & $1^{\pi}$ \\
\hline & Mean-diff & -3.46 & -4.33 & -2.7 & n.a. & n.a. \\
\hline & $t / d f$ & $12.18 / 70$ & $8.97 / 41$ & $7.18 / 22$ & n.a. & n.a. \\
\hline & $\mathrm{p}$-value & $<.000$ & $<.000$ & $<.000$ & n.a. & n.a. \\
\hline & Effect size $d$ & 0.66 & & & & \\
\hline \multirow{4}{*}{ OASIS ${ }^{\S}$ pre-treatment } & Min & 0 & 0 & 0 & 0 & 5 \\
\hline & Max & 17 & 17 & 8 & 12 & 14 \\
\hline & $\mathrm{M}$ & 6.20 & 6.57 & 5.30 & 6.64 & 7.80 \\
\hline & SD & 4.35 & 4.83 & 3.79 & 3.47 & 3.56 \\
\hline \multirow{3}{*}{ OASIS post-treatment } & Min & 0 & 0 & 0 & 0 & 11 \\
\hline & Max & 18 & 18 & 8 & 7 & 11 \\
\hline & M & 3.63 & 4.19 & 2.13 & 4.40 & 11.0 \\
\hline
\end{tabular}




\begin{tabular}{|c|c|c|c|c|c|c|}
\hline & SD & 4.07 & 4.62 & 2.45 & 2.70 & 0.00 \\
\hline \multirow{5}{*}{ OASIS post minus pre } & $\mathrm{n}$ & 71 & 42 & 23 & $5^{\pi}$ & $1^{\pi}$ \\
\hline & Mean-diff & -2.57 & -2.38 & -3.17 & n.a. & n.a. \\
\hline & & $7.51 / 70$ & $5.86 / 41$ & $4.16 / 22$ & n.a. & n.a. \\
\hline & p-value & $<.000$ & $<.000$ & $<.000$ & n.a. & n.a. \\
\hline & Effect size $d$ & 0.61 & & & & \\
\hline \multirow{4}{*}{ SOFAS " pre-treatment } & Min & 50 & 50 & 55 & 51 & 64 \\
\hline & Max & 91 & 90 & 90 & 91 & 75 \\
\hline & M & 69.9 & 69.4 & 70.5 & 71.2 & 67.2 \\
\hline & SD & 9.67 & 9.89 & 8.42 & 13.83 & 5.18 \\
\hline \multirow{4}{*}{ SOFAS post-treatment } & Min & 55 & 55 & 55 & 55 & 68 \\
\hline & Max & 95 & 95 & 90 & 95 & 70 \\
\hline & M & 75.6 & 77 & 75.1 & 73 & 69.3 \\
\hline & SD & 9.63 & 9.48 & 9.32 & 13.42 & 1.15 \\
\hline \multirow{5}{*}{ SOFAS post minus pre } & $\mathrm{n}$ & 87 & 42 & 35 & $7^{\mathbb{\pi}}$ & $3^{\pi}$ \\
\hline & Mean-diff & 5.31 & 6.85 & 3.88 & 5.0 & 1.0 \\
\hline & $t / d f$ & $74.5 / 89$ & $53.8 / 43$ & $48.3 / 35$ & n.a. & n.a. \\
\hline & p-value & $<.000$ & $<.000$ & $<.000$ & n.a. & n.a. \\
\hline & Effect size $d$ & 0.59 & & & & \\
\hline \multirow{8}{*}{$\begin{array}{l}\text { Clinical Stages* at first (pre) } \\
\text { and final (post) session }\end{array}$} & Stage & Pre (n) & Pre (\%) & Post (n) & Post (\%) & \\
\hline & $\mathrm{N}^{\wedge}$ & 48 & 58.6 & 48 & 58.6 & \\
\hline & Stage 0 & 8 & 16.7 & 19 & 39.6 & \\
\hline & Stage 1a & 27 & 56.3 & 25 & 52.1 & \\
\hline & Stage $1 b$ & 6 & 12.5 & 2 & 4.2 & \\
\hline & Stage 2 & 6 & 12.5 & 2 & 4.2 & \\
\hline & Stage 3 & 0 & 0 & 0 & 0 & \\
\hline & Stage 4 & 1 & 2.1 & 0 & 0 & \\
\hline \multicolumn{7}{|c|}{ 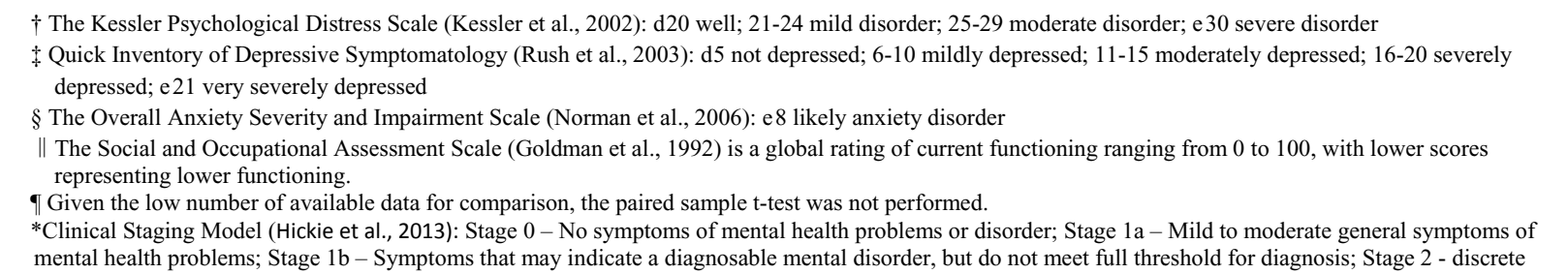 } \\
\hline
\end{tabular}


disorders; Stage 3 - recurrent or persistent disorder; Stage 4 - severe, persistent and unremitting illness.

$\wedge$ Data on 'clinical staging' was only available for young people seen since January 2015 in line with headspace Minimum Data Set access restrictions reducing the sample size to $\mathrm{n}=48$.

\section{Table 3: Cross-tabulations of selected variables and 'favourable' vs. 'unfavourable' treatment outcomes on psychometric measures (K10, QIDS, OASIS, SOFAS) ${ }^{\dagger}$}

\begin{tabular}{|c|c|c|c|c|}
\hline & $\mathrm{n}$ & $\lambda^{2}$ & df & $\mathrm{p}$ \\
\hline Gender (Male/Female) x Changes on the K10 & 77 & .044 & 1 & .834 \\
\hline Gender (Male/Female) x Changes on the QIDS & 71 & .006 & 1 & .937 \\
\hline Gender (Male/Female) x Changes on the OASIS & 71 & .028 & 1 & .866 \\
\hline Gender (Male/Female) x Changes on the SOFAS & 87 & 1.82 & 1 & .176 \\
\hline Age-groups (12-14yrs; $15-17 \mathrm{yrs} ; 18-20 \mathrm{yrs} ; 21-23 \mathrm{yrs} ;>24 \mathrm{yrs}) \mathrm{x}$ Changes on the K10 & 77 & 1.22 & 4 & .874 \\
\hline Age-groups (12-14yrs; 15-17yrs; 18-20yrs; 21-23yrs; >24yrs) x Changes on the QIDS & 71 & 3.58 & 4 & .466 \\
\hline Age-groups (12-14yrs; 15-17yrs; 18-20yrs; 21-23yrs; >24yrs) x Changes on the OASIS & 71 & 8.18 & 4 & .085 \\
\hline Age-groups (12-14yrs; 15-17yrs; 18-20yrs; 21-23yrs; >24yrs) x Changes on the SOFAS & 87 & 1.84 & 2 & .396 \\
\hline Centre attended (Sunshine; Glenroy; Craigieburn; Werribee) x Changes on the K10 & 77 & 8.75 & 3 & .033 \\
\hline Centre attended (Sunshine; Glenroy; Craigieburn; Werribee) x Changes on the QIDS & 71 & 2.43 & 3 & .488 \\
\hline Centre attended (Sunshine; Glenroy; Craigieburn; Werribee) x Changes on the OASIS & 71 & 5.09 & 3 & .165 \\
\hline Centre attended (Sunshine; Glenroy; Craigieburn; Werribee) x Changes on the SOFAS & 87 & 1.69 & 3 & .637 \\
\hline
\end{tabular}

Table 4: Young people's responses to questions regarding their experience in the $\mathrm{BIC}^{\dagger}$

\begin{tabular}{|l|c|c|c|c|c|}
\hline$(\mathrm{n}=67)$ & Min & Max & M & SD & $\%{ }^{\ddagger}$ \\
\hline My initial assessment experience was supportive and positive & 3 & 6 & 5.48 & .785 & $91.3 \%$ \\
\hline The Brief Interventions Clinic was explained to me appropriately & 4 & 6 & 5.49 & .587 & $91.5 \%$ \\
\hline The Brief Interventions Clinic met my expectations & 4 & 6 & 5.45 & .634 & $90.8 \%$ \\
\hline
\end{tabular}

This article is protected by copyright. All rights reserved. 


\begin{tabular}{|c|c|c|c|c|c|}
\hline I felt understood and heard by my therapist & 5 & 6 & 5.88 & .327 & $98.0 \%$ \\
\hline I felt supported by my therapist & 5 & 6 & 5.84 & .373 & $97.3 \%$ \\
\hline I would recommend the Brief Interventions Clinic to a friend & 3 & 6 & 5.66 & .641 & $94.3 \%$ \\
\hline $\begin{array}{l}\text { Overall, I am satisfied with my experience in the Brief Interventions } \\
\text { Clinic }\end{array}$ & 4 & 6 & 5.70 & .493 & $95.0 \%$ \\
\hline \multicolumn{6}{|l|}{${ }^{\dagger}$ Based on 7-point Likert Scale ratings: $0=$ not at all to $6=$ definitely } \\
\hline
\end{tabular}

\begin{tabular}{|c|c|c|c|c|}
\hline $\begin{array}{l}\text { Theme 1: } \\
\text { Therapeutic } \\
\text { relationship }(\mathrm{N}=53)\end{array}$ & $\begin{array}{l}\text { Theme 2: } \\
\text { Coping } \\
\text { strategies/problem } \\
\text { solving skills } \\
(\mathrm{N}=32)\end{array}$ & $\begin{array}{l}\text { Theme 3: } \\
\text { Changes and } \\
\text { outcomes }(\mathrm{N}=22)\end{array}$ & $\begin{array}{l}\text { Theme 4: } \\
\text { BIC content and } \\
\text { processes }(\mathrm{N}=29)\end{array}$ & $\begin{array}{l}\text { Theme 5: } \\
\text { Suggestions for } \\
\text { improvement } \\
(\mathrm{N}=23)\end{array}$ \\
\hline $\begin{array}{l}\text { Felt heard, } \\
\text { supported and } \\
\text { understood }(n=25)\end{array}$ & $\begin{array}{l}\text { Learned specific } \\
\text { coping } \\
\text { skills/strategies } \\
(n=16)\end{array}$ & $\begin{array}{l}\text { Improvement in } \\
\text { current } \\
\text { difficulties/problems } \\
(n=12)\end{array}$ & $\begin{array}{l}\text { Choice of } \\
\text { modules/flexible } \\
\text { modular approach } \\
(n=8)\end{array}$ & $\begin{array}{l}\text { Access (after hour } \\
\text { sessions, less travel } \\
\text { distance) }(n=2)\end{array}$ \\
\hline $\begin{array}{l}\text { Comfortable talking } \\
\text { about } \\
\text { problems/concerns } \\
(n=14)\end{array}$ & $\begin{array}{l}\text { Increased } \\
\text { understanding of } \\
\text { difficulties }(n=12)\end{array}$ & $\begin{array}{l}\text { Improved } \\
\text { management of } \\
\text { anger }(n=6)\end{array}$ & $\begin{array}{l}\text { Interactive sessions } \\
\text { with psycho- } \\
\text { education and skill- } \\
\text { building }(n=7)\end{array}$ & $\begin{array}{l}\text { Duration (additional } \\
\text { sessions available) } \\
(n=2)\end{array}$ \\
\hline $\begin{array}{l}\text { Listened to without } \\
\text { judgment }(n=9)\end{array}$ & $\begin{array}{l}\text { Benefited from } \\
\text { learning relaxation } \\
\text { and mindfulness } \\
\text { strategies }(n=4)\end{array}$ & $\begin{array}{l}\text { Reduction of } \\
\text { distress/difficult } \\
\text { emotions }(n=4)\end{array}$ & $\begin{array}{l}\text { Specific module } \\
\text { content }(n=7)\end{array}$ & $\begin{array}{l}\text { More activities } \\
(n=1)\end{array}$ \\
\hline $\begin{array}{l}\text { Experienced open } \\
\text { and strong } \\
\text { communication } \\
(n=5)\end{array}$ & - & - & $\begin{array}{l}\text { Positive mental } \\
\text { health service } \\
\text { experience }(n=5)\end{array}$ & $\begin{array}{l}\text { Simpler language } \\
(n=1)\end{array}$ \\
\hline - & - & - & $\begin{array}{l}\text { Regular weekly } \\
\text { sessions }(n=2)\end{array}$ & $\begin{array}{l}\text { None/expectations } \\
\text { met }(n=17)\end{array}$ \\
\hline \multicolumn{5}{|c|}{$\begin{array}{l}\text { Note: } \mathrm{N}=90 \text { respondents to most liked question; } \mathrm{N}=23 \text { respondents to suggestions for improvement question. } \\
\text { Category N's are greater than total number of participants as responses were associated with multiple themes. }\end{array}$} \\
\hline
\end{tabular}




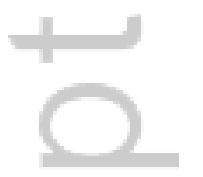

This article is protected by copyright. All rights reserved. 


\section{University Library}

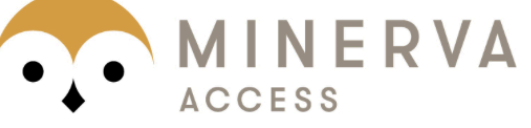

A gateway to Melbourne's research publications

Minerva Access is the Institutional Repository of The University of Melbourne

Author/s:

Schley, C;Pace, N;Mann, R;McKenzie, C;McRoberts, A;Parker, A

Title:

The headspace Brief Interventions Clinic: Increasing timely access to effective treatments for young people with early signs of mental health problems

Date:

2019-10-01

\section{Citation:}

Schley, C., Pace, N., Mann, R., McKenzie, C., McRoberts, A. \& Parker, A. (2019). The headspace Brief Interventions Clinic: Increasing timely access to effective treatments for young people with early signs of mental health problems. EARLY INTERVENTION IN PSYCHIATRY, 13 (5), pp.1073-1082. https://doi.org/10.1111/eip.12729.

Persistent Link:

http://hdl.handle.net/11343/284482 